\title{
Two Subsequent Metachroneus Solid Tumors: Oncocytic Variant Adrenocortical Carcinoma and Rhabdomyosarcoma of Childhood: Case Report and Literature Review
}

\author{
(D) Onur Akın, (D) Erman Ataş, (D) İrem Ayşe Atasoy, (1) Nihal Durmaz, (D) Ömer Kartal \\ University of Health Sciences Turkey, Gülhane Training and Research Hospital, Clinic of Pediatrics, Ankara, Turkey
}

\begin{abstract}
What is already known on this topic?
Adrenocortical carcinoma can be related to other cancers.
\end{abstract}

\section{What this study adds?}

Sequence analysis should be performed if fluorescence in situ hybridization analysis is negative. Analysis of Hounsfield unit density of the tumor on imaging can help to distinguish malign from benign. The Lin-Weiss-Bisceglia system should be used instead of the Weiss system for the oncocytic variant.

\begin{abstract}
Most cases of malignancies appear to be sporadic, but some syndromes are associated with malignancies with germline variants. Herein, a child with an unusual association of oncocytic variant adrenocortical carcinoma (ACC) and rhabdomyosarcoma (RMS) was presented. An 18-month-old-boy was admitted with virilization of the genital area, penis enlargement and erection, which had begun six months earlier. Serum total testosterone (457 ng/dL; NR < 10), androstenedione (3.35 ng/mL; NR < 0.5) and dehydroepiandrosterone$\mathrm{SO}_{4}(206 \mathrm{mcg} / \mathrm{dL}$; NR <35) were above the normal ranges. Right adrenal mass was detected. After adrenalectomy, histopathological examination revealed an oncocytic variant ACC. Three-month after surgery, he then presented with $6 \times 8 \mathrm{~cm}$ sized swelling of the left leg. Histopathological examination revealed embryonal RMS. Testing for tumor protein (TP53) variant by DNA sequence analysis was positive; however; fluorescence in situ hybridization analysis was negative. After chemotherapy and local radiotherapy, the patient is in good condition without tumor recurrence. Only about one-third of these tumors have a variant of TP53. This status also applies to other genetic variants related to cancer. However, a significant association of malignancies strongly suggests a problem in tumor suppressor genes or new variants. Another as yet unidentified suppressor gene may also be present and effective in this locus. The occurrence of ACC as a part of a syndrome and positive family history of malignancies in patients are clinically important. These patients and their families should be scanned for genetic abnormalities. The patient with ACC should be followed-up carefully for other tumors to detect malignancy early.
\end{abstract}

Keywords: Child, adrenocortical carcinoma, oncocytic variant, rhabdomyosarcoma, TP53

\section{Introduction}

Oncocytic variant adrenocortical carcinoma (ACC) is an extremely rare tumor, with an incidence of 0.72 per million of population annually $(1,2)$. In our country, ACCs account for $6.9 \%$ of carcinomas and other malignant epithelial tumors, and $0.19 \%$ of childhood cancers (3). Only 147 cases with adrenal oncocytic neoplasm have been reported in the literature (4). Although most cases of ACCs are sporadic, ACCs have an association with hereditary cancer syndromes such as Li-Fraumeni syndrome (LFS) and Beckwith-Wiedemann syndromes (BWS) (5). The pathogenesis of sporadic ACCs is less well understood. Tumor suppressor genes have a
Address for Correspondence: Erman Ataş MD, University of Health Sciences Turkey, Gülhane Training and Research Hospital, Clinic of Pediatrics, Ankara, Turkey

Phone: +90312304 4395 E-mail: eatasdr@gmail.com ORCID: orcid.org/0000-0002-6758-6208
Conflict of interest: None declared Received: 25.03 .2020 Accepted: 02.06.2020

${ }^{\circ}$ Copyright 2021 by Turkish Pediatric Endocrinology and Diabetes Society

The Journal of Clinical Research in Pediatric Endocrinology published by Galenos Publishing House. 
significant role in the development of cancer (6). Breast cancer, soft tissue and bone sarcoma, brain tumors, Wilms' tumor, neuroblastoma, and hepatoblastoma are some types of cancer that are associated with ACCs. However, well-known oncogenes/tumor suppressor variants are not relevant to each malignancy. Environmental factors and decreased penetrance of a particular gene defect cannot be excluded (6).

In this report, we described clinical features of an oncocytic variant ACC presenting as peripheral precocious puberty, and in whom embryonal rhabdomyosarcoma (RMS) developed as a second malignancy. Moreover, the genetic variant is discussed.

\section{Case Report}

An 18-month-old-boy was admitted at the department of pediatric endocrinology with virilization of the genital area, penis enlargement and erection, which had begun six months earlier. Informed consent was obtained from the parents of the patients. There were no relevant features in his personal nor his family history. There is no consanguinity.

\section{Anthropometric Evaluation}

At presentation his height was $86 \mathrm{~cm}$ ( $78^{\text {th }}$ percentile), weight $14.5 \mathrm{~kg}$ ( $95^{\text {th }}$ percentile), chronological/height ages were 1.61/1.88 years old, height standard deviation score (SDS)/target height/target height SDS were $+0.80 / 165 \mathrm{~cm} /$ 1.65 , respectively. The gap between height SDS and target height SDS was likely due to accelerated growth velocity. Although the patient had phallic enlargement and pubarche for six months, his testicular size was consistent with the prepubertal period with $2 \mathrm{~mL} / 2 \mathrm{~mL}$. Hemihypertrophy was not detected.

\section{Laboratory Evaluation}

Biochemical and complete blood count tests were within normal limits. His bone age was advanced and compatible with three years. Serum analytes wereall in the normal range as follows: follicle-stimulating hormone $=0.3 \mathrm{IU} / \mathrm{L}$ (NR 0.3-4.6), luteinizing hormone $=0.12 \mathrm{IU} / \mathrm{L}$ (NR 0.16.0), $17-\mathrm{OH}$ progesterone $=0.5 \mathrm{ng} / \mathrm{mL} \quad(\mathrm{NR}$ 0.1-0.9), $\mathrm{T} 4=0.96 \mathrm{ng} / \mathrm{dL} \quad$ (NR 0.81-1.73), thyroid stimulating hormone $=2.84 \mathrm{mIU} / \mathrm{mL}$ (NR 0.8-6.26), adrenocorticotropic hormone $=21.7 \mathrm{pg} / \mathrm{mL}$ (NR 0-46), cortisol $=10.7 \mathrm{mcg} / \mathrm{dL}$ (NR 4.3-22.4), beta-human chorionic gonadotropin $<0.2$ $\mathrm{IU} / \mathrm{mL}$ (NR 0-10), alpha-fetoprotein $=2.1 \mathrm{ng} / \mathrm{mL}$ (NR 0-8.1) and urinary vanillylmandelic acid $=2.5 \mathrm{mg} / \mathrm{g}$ creatinine $(\mathrm{NR}<18)$. However, serum total testosterone $457 \mathrm{ng} / \mathrm{dL}$
$(\mathrm{NR}<10)$, androstenedione $3.35 \mathrm{ng} / \mathrm{mL}(\mathrm{NR}<0.5)$ and dehydroepiandrosterone (DHEA)-SO $206 \mathrm{mcg} / \mathrm{dL}(\mathrm{NR}<35$ ) were all above the normal range.

\section{Radiologic Evaluation}

Abdominal ultrasonography (USG) revealed right adrenal, $22 \times 17 \mathrm{~mm}$-sized mass. Scrotal ultrasound was normal. Magnetic resonance imaging (MRI) revealed a $16 \times 14 \times 17$ $\mathrm{mm}$ mass, which was isointense with muscle in $\mathrm{T} 1$ and hyperintense in $\mathrm{T} 2$ images. Abdominal computed tomography (CT) showed a 16x11 mm nodular, hypodense mass of 35 Hounsfield units (HUs).

\section{Surgery, Pathology and Hormonal Changes}

The patient underwent adrenalectomy, and the mass was resected in one piece. Histopathological examination revealed oncocytic variant ACC with a weight of $50 \mathrm{~g}$ and a volume of $2 \mathrm{~cm}^{3}$. Histologically, the surgical border of the tumor, which was limited to the adrenal gland and capsule of the adrenal gland was intact. Neoplastic tissue had an expansile pattern. Normal adrenocortical cell components were seen in some sections and mixed with neoplastic cells. Retroperitoneal lymph node involvement and vascular invasion were not seen. Immunohistochemical analysis was positive for adrenal cortical specific markers "MART-1 and inhibin", neuroendocrine and adrenal medulla/cortex marker "synaptophysin", and negative for adrenal medulla stain "chromogranin" and marker of Schwann cell "solubility in $100 \%$ saturated ammonium sulfate at neutral pH (S100)", and renal epithelial marker "epithelial membrane antigen (EMA)". The Ki-67 proliferation index was $10 \%$. Twenty mitoses were counted per 50 high power fields with the help of cell proliferation marker "Phospho-Histone H3 (PHH3)" (Figure 1). Serum total testosterone, androstenedione and DHEA-SO 4 levels decreased to $<10 \mathrm{ng} / \mathrm{mL},<0.3 \mathrm{ng} / \mathrm{mL}$ and $102 \mathrm{mcg} / \mathrm{dL}$ at the $12^{\text {th }}$ postoperative hour and $<10 \mathrm{ng} / \mathrm{mL}$, $<0.3 \mathrm{ng} / \mathrm{mL}$ and $57 \mathrm{mcg} / \mathrm{dL}$ at the $24^{\text {th }}$ postoperative hour (Table 1).

\section{Treatment}

Positron emission tomography (PET)-CT and thoracoabdominal CT were reported normal as part of the staging workup. Staging of this oncocytic variant ACC, according to the Children's Oncology Group (7) classification was evaluated as stage 1 . No further therapy was planned due to the group 1 staging (complete resection and tumor volume $<200 \mathrm{~cm}^{3}$ and negative markers after surgery) according to TREP (Rare Tumors in Pediatric Age) (8). No further medical treatment was given to the patient. He was followed-up closely with physical examination and USG. 

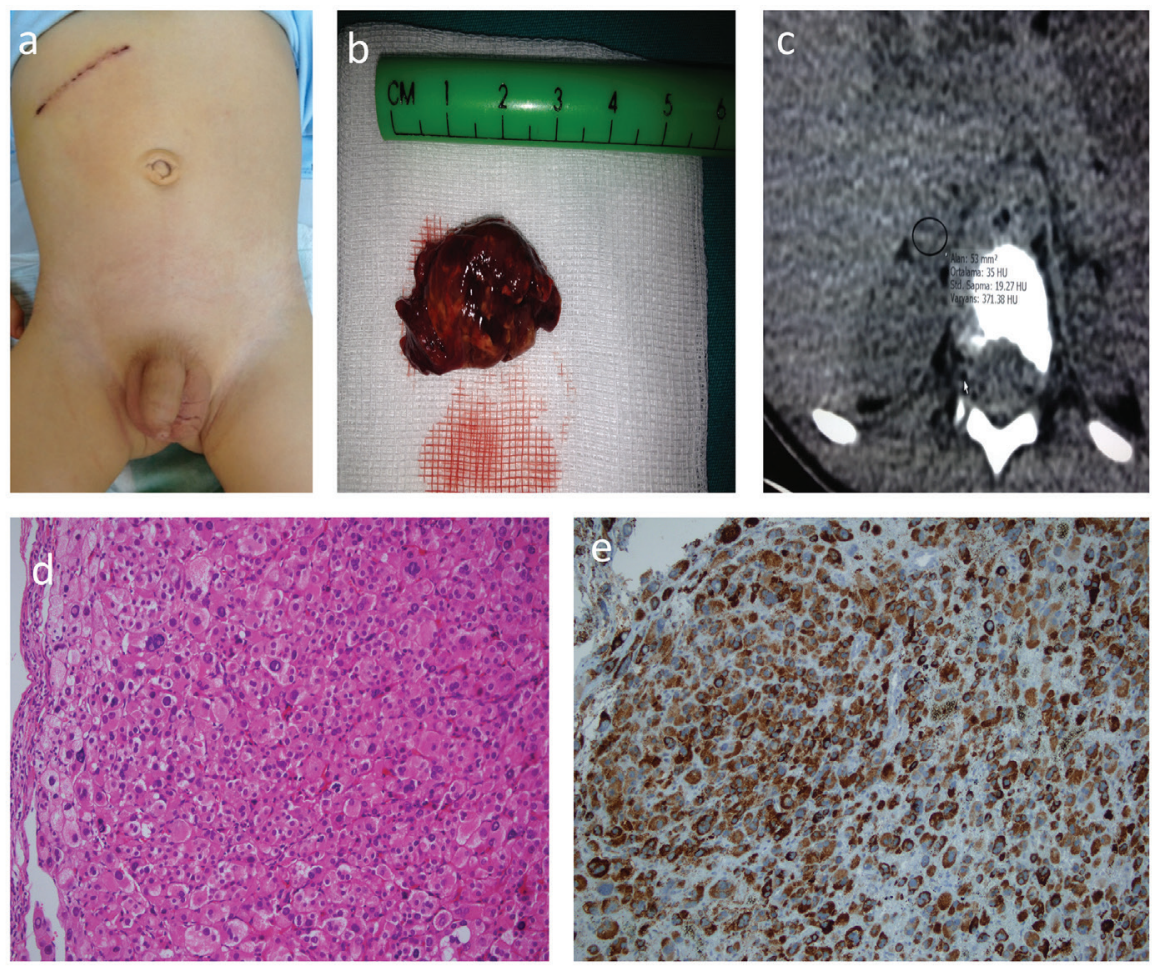

Figure 1. a) Enlargement of phallus, stage 2 pubic hair development. b) Abdominal computed tomography showing right adrenocortical carcinoma. c) The mass after adrenelectomy. d) Oncocytic adrenocortical carcinoma, oxyphilic cell population, hematoxylineosin, immunohistochemical expression, (magnification x200). e) Oncocytic adrenocortical carcinoma, Melan-A (MART-1) immunohistochemical expression, (magnification x200)

\section{Evaluation After Relapse}

Three months after adrenalectomy, the child represented with swelling of the left leg with a few weeks of history. A painless, immobile, rough, $6 \times 8 \mathrm{~cm}$ swelling between the proximal anteroposterior femoral and the inguinal region was detected. MRI scanning revealed $9 \times 4 \times 3.5 \mathrm{~cm}$ mass, which was isointense with muscle in T1, hyperintense in T2 images with dense contrast enhancement. The mass compressed to the superficial femoral vein and surrounded the femoral artery for 200/360 degrees. A tru-cut biopsy was performed. The pathology result was reported as compatible with metastasis of oncocytic variant ACC without immunohistochemistry. After extensive resection of the mass, histopathological examination revealed embryonal RMS, which was $8.5 \times 5 \times 4 \mathrm{~cm}$, with a grey-white color, and solid (Figure 2). Histologically, the surgical border of the tumor, which was limited to muscle was intact with $5 \%$ focal necrosis. Lymphovascular invasion was not detected. Immunohistochemical analysis was positive for desmin, Myo-D1, and muscle-specific-actin. MART-1, synaptophysin, S100, inhibin, chromogranin, CK7, CK20, MPO, and EMA were negative. The Ki-67 proliferation index was $70 \%$ (Figure 2). PET-CT and thoraco-abdominal CT evaluation were found

\begin{tabular}{|c|c|c|c|}
\hline & Preoperative & $\begin{array}{l}\text { Postoperative } \\
12^{\text {th }} \text { hour }\end{array}$ & $\begin{array}{l}\text { Postoperative } \\
24^{\text {th }} \text { hour }\end{array}$ \\
\hline $\begin{array}{l}\text { Total testosteron } \\
\text { (ng/dL) }\end{array}$ & 457 & $<10$ & $<10$ \\
\hline $\begin{array}{l}\text { Androstenedion } \\
(\mathrm{ng} / \mathrm{mL})\end{array}$ & 3.35 & $<0.3$ & $<0.3$ \\
\hline $\begin{array}{l}\text { DHEA-SO }{ }_{4}(\mathrm{mcg} / \\
\mathrm{dL})\end{array}$ & 206 & 102 & 57 \\
\hline
\end{tabular}

DHEA-SO $_{4}$ : dehydroepiandrosterone

to all be normal as part of the staging workup. Lymph node and pulmonary involvement were not detected. The extent of the RMS was defined according to the Intergroup RMS study (IRS) 3 staging system. The patient was evaluated as pretreatment stage 3, postoperative group 1, and low subset B risk.

\section{Genetic Evaluation}

A pedigree chart was made. No consanguinity was present. Karyotype analysis of the patient was normal (46; XY). Testing for tumor protein (TP53) variant by DNA sequence analysis was positive in the peripheral blood sample, but fluorescence in situ hybridization was negative. 

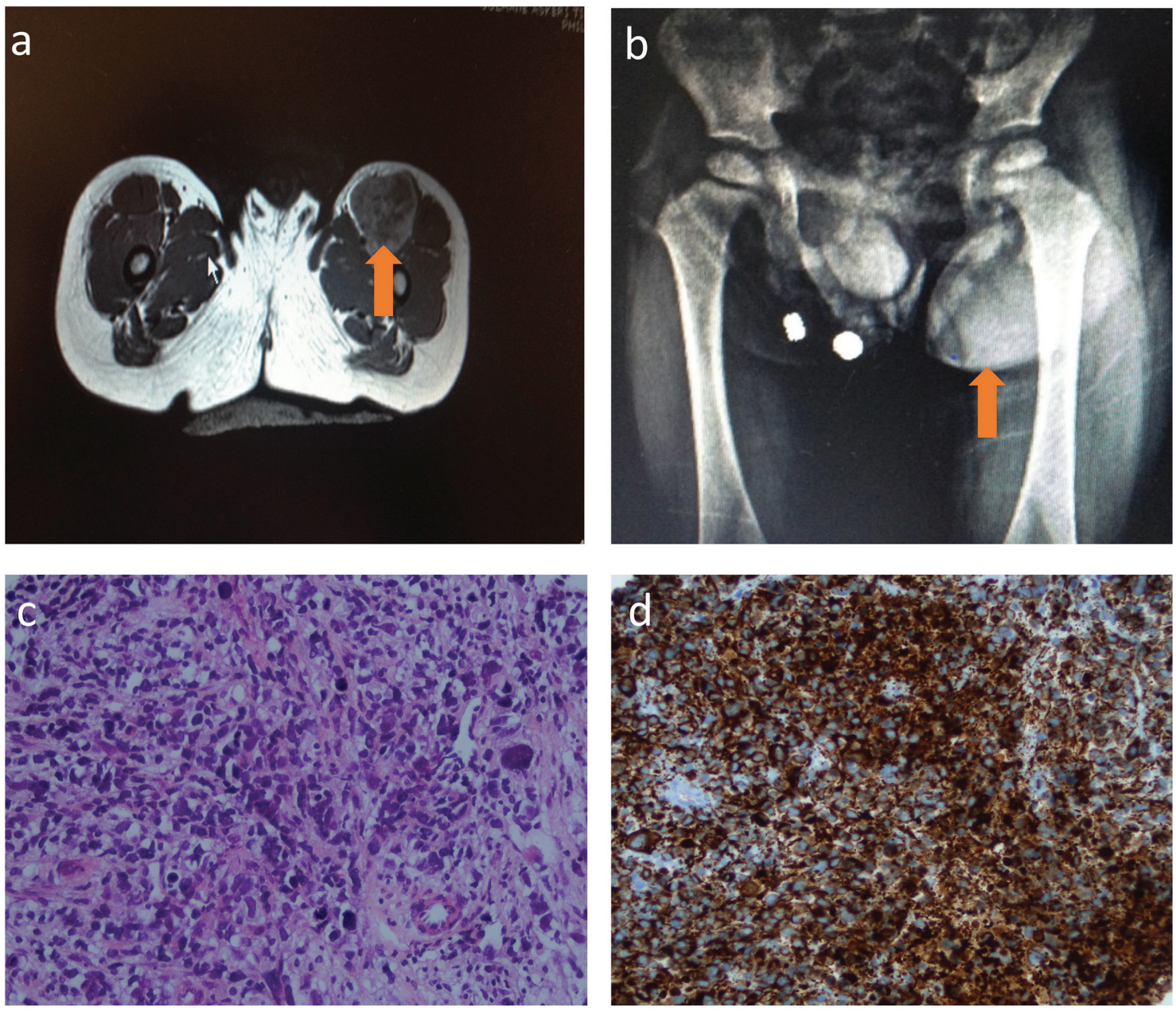

Figure 2. a) Femoral magnetic resonance imaging showing left side rhabdomyosarcoma. B) X-ray graphy showing left femoral mass. c) Rhabdomyosarcoma, hematoxylin-eosin, (magnification x400). d) Rhabdomyosarcoma, Desmin positivity, (magnification x200)

\section{Treatment}

The patient was treated with chemotherapy consisting of vincristine, cyclophosphamide, and actinomycin-D according to the protocol POG D-9602-VAC. Revision of pathological samples was performed again. Sarcomatous component of the oncocytic variant ACC was not found. The patient was evaluated ten weeks after starting the VAC regimen, and he was in remission at both the ACC and RMS sites. His disease was discussed with the radiotherapy department for local therapy of extremity RMS. Radiation oncology refused to give radiation therapy owing to remission of disease and because the patient was aged under three years. At the $24^{\text {th }}$ week of treatment, a $2 \times 2 \mathrm{~cm}$ sized, inguinal mass in the left sartorius muscle, which was enhanced after injection of contrast agent, and compatible with lymphadenopathy was detected with MRI. The mass was excised, and the pathological result was compatible with RMD metastasis. The patient was evaluated as relapse and progression under chemotherapy treatment, and the treatment was changed with ifosfamide, carboplatin, etoposide (ICE) regimen. After three cycles, he was in remission. Radiotherapy was given for local control of RMS. After the sixth cycle of ICE, the patient was in good condition with no tumor recurrence, and treatment was stopped. However, he came back six months later with left leg pain due to a mass and the masseffect on the femoral artery and nerve. Thrombosis and malign mesenchymal tumour protocol and sorafenib were started. Surgeons recommended amputation due to nerve and lymphatic invasion of the tumor. However, the patient family refused the amputation. He died, due to progressive disease, 2.5 years after diagnosis.

\section{Discussion}

Although most cases of malignancies appear to be sporadic, some syndromes that are associated with malignancy or malignancies can be detected in oncology practice. Even if an association is not found, unusual associated malignancies can be evaluated for germline variants. In this study, we 
aimed to describe an association of cancers with no family history in a child with oncocytic variant ACCs and RMS with the help of genetic evaluation.

Patients with LFS, BWS, and multiple endocrine neoplasia type 1 (MEN-1) are at risk for developing certain types of cancers, such as ACC and RMS (9). LFS especially is associated with a $40 \%$ risk of malignancy before the age of 16 years, high mortality rates, and second primary malignancies, and is an autosomal disorder $(10,11)$. TP53 tumor suppressor gene on chromosome 17 p13 in LFS, GNAS 1 variant and abnormalities of 11 p15.5 in BWS and variants of the MEN1 gene on chromosome $11 \mathrm{q} 13$ in MEN-1 may be detected in some patients with malignancy $(12,13,14,15)$. Six per cent of patients with second malignancies and no familial features of LFS had a germline TP53 variant in a sample of 59 patients (16). Germline TP53 variants with no familial features of LFS are identified in $50-80 \%$ of children with ACC and $10 \%$ with RMS $(17,18)$. A variant related to malignancy may not be detected, as was the case in our patient. In this study, an extensive pedigree was obtained. No family history of any other malignancies was documented in this family. Our patient did not have clinical features of BWS and McCune-Albright syndrome. Thus, we decided to evaluate genetically because of sporadic malignancy.

ACC is an extremely rare tumour. It accounts for $0.2 \%$ of childhood cancers (12). In our country, ACC accounts for $6.9 \%$ of carcinomas and other malignant epithelial tumours, and $0.19 \%$ of childhood cancer (3). Although most cases of ACCs appear to be sporadic, some have been described as a component of several hereditary cancer syndromes (9). Virilization can be seen owing to increased DHEA and DHEA-SO ${ }_{4}$ production (13). In this case, DHEA$\mathrm{SO}_{4}$, androstenedione, and testosterone were all above the reference range contemporary with virilization. The absence of hormonal hyperactivity is associated with poor prognosis because of the advanced stage of the tumor at diagnosis (14). The hormonally active status of this case was very significant in early diagnosis together with the evident virilization. The levels of total testosterone, androstenedione, DHEA-SO ${ }_{4}$ were highly elevated at the time of diagnosis. After surgery, the levels of these hormones decreased to an average level in the $24^{\text {th }}$ hour. The survival rates of stage 1 are higher than others (15). Our patient was followedup without treatment after surgery. The primary site was normal in the follow-up.

Oncocytic variant ACC is a rare disease with low incidence. More than $80 \%$ are benign or with low malignant potential. It has been described in only 147 cases between 1986 and $2013(4,16,17)$. Eighty per cent were detected incidentally owing to non-functional adrenal mass (4). In addition to this, a sarcomatous component may be present (1). RMS as a second cancer developed in the follow-up. RMS represents $6.5 \%$ of childhood cancers, and $52.9 \%$ of soft tissue sarcomas (3). Somatic variants of the TP53 gene can be seen in as many as $50 \%$ of cases. However, germline variants are much less common and tend to be associated with a lower age (average age 22 months) at presentation $(18,19)$. Although this case was hormonally active, the sarcomatous component was not found.

There is no definitive pattern on CT scan or MRI (4). On the CT Hounsfield Scale, adenoma/hyperplasia and carcinoma are assigned a value of $16.2 \pm 13.6$ and $36.9 \pm 4.1$, respectively (20). Specificity and sensitivity of PET-CT are $>95 \%$ (21). The mass was compatible with non-adenoma owing to a Hounsfield Scale value of 35 HU. PET-CT was performed after surgery. Evaluation of disease with PET-CT was normal in staging workup.

Clinicopathological, oncocytic variant ACC differs from conventional ACC. There is no preference for males or females. It is smaller and lighter than conventional ACC and tends to hold the left side. The oncocytic variant has rare mitoses including no atypia, low rate of necrosis, fibrosis, and venous, sinusoidal, and capsular invasion (22). These features were mostly compatible with the pathology and clinical features in our case, except the high mitotic rate and involvement of the right side.

Proposed major criteria including a mitotic rate of more than five mitoses per 50 high power fields, any atypical mitoses or venous invasion, and minor criteria including large size/weight ( $>10 \mathrm{~cm}$ and > $200 \mathrm{~g}$ ), necrosis, capsular invasion or sinusoidal invasion, have been investigated for distinguishing malignant tumors by Bisceglia et al (23). Defining criteria for oncocytic tumors have been outlined that include predominantly cells with eosinophilic and granular cytoplasm, a high nuclear grade, and a diffuse architectural pattern. The presence of one major criterion indicates malignancy, 1-4 minor criteria indicating uncertain malignant potential (borderline) and the absence of all major and minor criteria are indicative of a benign mass. In the case presented the mitotic rate was more than five mitoses per 50 high power fields. When mitosis was evaluated with PHH3, 20 mitoses were counted per 50 high power fields. Venous, capsular, and sinusoidal invasions and necrosis were not detected. Thus the ACC tumor in our patient met all defining criteria. The mass < $100 \mathrm{~g}$ was compatible with a good prognosis (24). Our patient was evaluated as stage 1 because his adrenal mass under $<100 \mathrm{~g}$ with total excision. However, it was assessed as a malign mass owing to the one major criterion present, that was a high mitotic rate. 
The molecular pathogenesis of sporadic ACCs is less well understood. Activation of proto-oncogenes and oncogenes on chromosome 4, 5, and 12 , and inactivation of tumor suppressor genes on chromosome arms $1 \mathrm{p}$ and $17 \mathrm{p}$ may be related to progression from adenoma to carcinoma (25). Loss of heterozygosity (LOH) at $17 \mathrm{p} 13$ is common, but only about one-third of these tumors are associated with a variant of TP53. However, TP53 might not be the only or major tumor suppressor gene at $17 \mathrm{p}$ related to ACCs. Another suppressor gene, which is as yet unidentified, may be present and effective in this locus and there is evidence to support this hypothesis (26). ACCs are associated with multiple somatic gene alterations and thus it is difficult to identify the exact genetic changes (27). Amplification of the steroidogenic factor-1 gene as well as germline TP53 variant in Southern Brazil, LOH of $11 \mathrm{p} 15$ with overexpression of insulin-like growth factor-2 as well as other growth-related tumor suppressor genes at this locus may explain this $(28,29)$.

\section{Study Limitations}

Unfortunately, there was only resource enough to investigate TP53 in this case, which is the limitation of our study. However, the TP53 variant was positive in sequence analysis.

Use of imaging techniques that use ionizing radiation, such as PET and CT scans, during the follow-up of this small child at risk of other malignancies was inadvisable. Therefore, MRI and abdominal USG were used to avoid repeated irradiation after the second malignancy. External radiotherapy to the leg after 10-weeks from the beginning of chemotherapy was not given by the radiotherapy department owing to remission of the disease. However, it was agreed to provide radiotherapy after the recurrence of the disease for local control.

The occurrence of ACC as a part of a syndrome is clinically significant because of the choice of treatment, caution with radiotherapy in patients with LFS, individualized screening for other cancers in these syndromes with mammography, colonoscopy, and identification family members at risk (30).

\section{Conclusion}

A multidisciplinary team approach, including oncology, surgery, endocrinology, pathology, radiation oncology, and genetic counselling is necessary. The cost-effectiveness of cancer screening with colonoscopy is not considered controversial for well-defined common cancers such as colon cancer, but no data are available for ACCs. Genetic evaluation should be suggested for patients with a second primary cancer. An unusual association of malignancies with the absence of a positive family history of malignancies strongly suggests a problem in tumor suppressor genes or new variants. The present case with an initial ACC tumor and a subsequent RMS tumor had a TP53 variant and inactivated TP53 is present in about half of all human cancers. Whole genome analyses will provide important information on the development of ACCs and secondary cancer in the future.

\section{Ethics}

Informed Consent: Informed consent was obtained from the parents of the patients.

Peer-review: Externally peer-reviewed.

\section{Authorship Contributions}

Surgical and Medical Practices: Erman Ataş, İrem Ayşe Atasoy, Nihal Durmaz, Concept: Onur Akın, Erman Ataş, Ömer Kartal, Design: Erman Ataş, Nihal Durmaz, Data Collection or Processing: Erman Ataş, İrem Ayşe Atasoy, Analysis or Interpretation: Onur Akın, Erman Ataş, Nihal Durmaz, Literature Search: Erman Ataş, İrem Ayşe Atasoy, Ömer Kartal, Writing: Onur Akın, Erman Ataş, İrem Ayşe Atasoy.

Financial Disclosure: The authors declared that this study received no financial support.

\section{References}

1. Thway K, Olmos D, Shah C, Flora R, Shipley J, Fisher C. Oncocytic adrenal cortical carcinosarcoma with pleomorphic rhabdomyosarcomatous metastases. Am J Surg Pathol 2012;36:470-477.

2. Bilimoria KY, Shen WT, Elaraj D, Bentrem DJ, Winchester DJ, Kebebew E, Sturgeon C. Adrenocortical carcinoma in the United States: treatment utilization and prognostic factors. Cancer 2008;113:3130-3136.

3. Kutluk MT, Yeşilipek A. Turkish National Pediatric Cancer Registry 2002-2008 (Turkish Pediatric Oncology Group and Turkish Pediatric Hematology Society). J Clin Oncol 2013;31(Suppl 15)10067.

4. Mearini L, Del Sordo R, Costantini E, Nunzi E, Porena M. Adrenal oncocytic neoplasm: a systematic review. Urol Int 2013;91:125-133. Epub 2012 Nov 8

5. Lodish MB, Stratakis CA. Rare and unusual endocrine cancer syndromes with mutated genes. Semin Oncol 2010;37:680-690.

6. Figueiredo BC, Stratakis CA, Sandrini R, DeLacerda L, Pianovsky MA, Giatzakis C, Young HM, Haddad BR. Comparative genomic hybridization analysis of adrenocortical tumors of childhood. J Clin Endocrinol Metab 1999;84:1116-1121.

7. Sandrini R, Ribeiro RC, DeLacerda L. Childhood adrenocortical tumors. J Clin Endocrinol Metab 1997;7:2027-2031.

8. Ferrari A, Bisogno G, De Salvo GL, Indolfi P, Perilongo G, Cecchetto G; Italian Study on Rare Tumours in Paediatric Age (TREP); Associazione Italiana Ematologia Oncologia Pediatrica (AIEOP). The challenge of very rare tumours in childhood: the Italian TREP project. Eur J Cancer 2007;43:654-659. Epub 2006 Oct 16

9. Koch CA, Pacak K, Chrousos GP. The molecular pathogenesis of hereditary and sporadic adrenocortical and adrenomedullary tumors. J Clin Endocrinol Metab 2002;87:5367-5384. 
10. Li FP, Fraumeni JF. Prospective study of a family cancer syndrome. JAMA 1982;247:2692-2694.

11. Eng C, Schneider K, Fraumeni JF, Li FP. Third international workshop on collaborative interdisciplinary studies of p53 and other predisposing genes in Li-Fraumeni syndrome. Cancer Epidemiol Biomarkers Prev 1997;6:379-383

12. Young JL, Miller RW. Incidence of malignant tumors in US children. J Pediatr 1975;86:254-258.

13. Del Gaudio AD, Del Gaudio GA. Virilizing adrenocortical tumors in adult women. Report of 10 patients, 2 of whom each had a tumor secreting only testosterone. Cancer 1993;72:1997-2003.

14. Neblett WW, Frexes-Steed M, Scott HW Jr. Experience with adrenocortical neoplasms in childhood. Am Surg 1987;53:11 7-125.

15. Dong D, Li H, Yan W, Ji Z, Mao Q. Surgical management and clinical prognosis of adrenocortical carcinoma. 2012;88:400-404. Epub 2012 Apr 5

16. Kakimoto S, Yushita Y, Sanefuji T, Kondo A, Fujishima N, Kishikawa M, Matsumoto K. Non-hormonal adrenocortical adenoma with oncocytoma-like appearances. Hinyokika Kiyo 1986;32:757-763.

17. de Krijger RR, Papathomas TG. Adrenocortical neoplasia: evolving concepts in tumorigenesis with an emphasis on adrenal cortical carcinoma variants. Virchows Arch 2012;460:9-18. Epub 2011 Nov 16

18. Felix CA, Kappel CC, Mitusdomi T, Nau NM, Tsokos M, Crouch GD, Nisen PD, Winick NJ, Helman LJ. Frequency and diversity of p53 mutations in childhood rhabdomyosarcoma. Cancer Res 1992;52:2243-2247.

19. Diller L, Sexsmith E, Gottlieb A, Li FP, Malkin D. Germline p53mutations are frequently deleted in young children with rhabdomyosarcoma. J Clin Invest 1995;95:1606-1611.

20. Hamrahian AH, Ioachimescu AG, Remer EM, Motta-Ramirez G, Bogabathina H, Levin HS, Reddy S, Gill IS, Siperstein A, Bravo EL. Clinical utility of noncontrast computed tomography attenuation value (hounsfield units) to differentiate adrenal adenomas/hyperplasias from nonadenomas: Cleveland Clinic experience. J Clin Endocrinol Metab 2005;90:871-877. Epub 2004 Nov 30

21. Gust L, Taieb D, Beliard A, Barlier A, Morange I, de Micco C, Henry JF, Sebag F. Preoperative 18F-FDG uptake is strongly correlated with malignancy, Weiss score, and molecular markers of agressiveness in adrenal cortical tumors. World J Surg 2012;36:1406-1410.
22. Song SY, Park S, Kim SR, Suh YL. Oncocytic adrenocortical carcinomas: a pathological and immunohistochemical study of four cases in comparison with conventional adrenocortical carcinomas. Pathol Int 2004;54:603-610.

23. Bisceglia M, Ludovico O, Di Mattia A, Ben-Dor D, Sandbank J, Pasquinelli G, Lau SK, Weiss LM. Adrenocortical oncocytic tumors: report of 10 cases and review of the literature. Int J Surg Pathol 2004;12:231-243.

24. Michalkiewicz E, Sandrini R, Figueiredo B, Miranda EC, Caran E, Oliveira-Filho AG, Marques R, Pianovski MA, Lacerda L, Cristofani LM, Jenkins J, Rodriguez-Galindo C, Ribeiro RC. Clinical and outcome characteristics of children with adrenocortical tumors: a report from the International Pediatric Adrenocortical Tumor Registry. J Clin Oncol 2004;22:838-845

25. Sidhu S, Marsh DJ, Theodosopoulos G, Philips J, Bambach CP, Campbell P, Magarey CJ, Russell CF, Schulte KM, Röher HD, Delbridge L, Robinson BG. Comparative genomic hybridization analysis of adrenocortical tumors. J Clin Endocrinol Metab 2002;87:3467-3474.

26. Libè R, Groussin L, Tissier F, Elie C, René-Corail F, Fratticci A, Jullian E, Beck-Peccoz P, Bertagna X, Gicquel C, Bertherat J. Somatic TP53 mutations are relatively rare among adrenocortical cancers with the frequent $17 \mathrm{p} 13$ loss of heterozygosity. Clin Cancer Res 2007;13:844850.

27. Koch CA, Pacak K, Chrousos GP. The molecular pathogenesis of hereditary and sopradic adrenocortical and adrenomedullary Tumors. J Clin Endocrinol Metab 2002;87:5367-5384.

28. Figueiredo BC, Cavalli LR, Pianovski MA, Lalli E, Sandrini R, Ribeiro RC, Zambetti G, DeLacerda L, Rodrigues GA, Haddad BR. Amplification of the steriodogenic factor 1 genein childhood adrenocortical tumors. J Clin Endocrinol Metab 2005;90:615-619. Epub 2004 Nov 16

29. Bourcigaux N, Gaston V, Logie A, Bertagna X, Le Bouc Y, Gicquel C. High expression of cyclin E and G1 CDK and loss of function of p57KIP2 are involved in proliferation of malignant sporadic adrenocortical tumors. J Clin Endocrinol Metab 2000;85:322-330.

30. Else T. Association of adrenocortical carcinoma with familial cancer susceptibility syndromes. Mol Cell Endocrinol 2012;351:66-70. Epub 2011 Dec 19 